\title{
Melting Time Prediction Model for Induction Furnace Melting Using Specific Thermal Consumption from Material Charge Approach
}

\author{
Onigbajumo Adetunji1 ${ }^{*}$, Seidu Saliu 0jo², Akinlabi Oyetunji², Newton Itua ${ }^{2}$ \\ ${ }^{1}$ School of Mechanical, Medical and Process Engineering, Queensland University of Technology, Brisbane, Australia \\ ${ }^{2}$ Department of Metallurgical and Materials Engineering, Federal University of Technology, Akure, Ondo State, Nigeria \\ Email: *a.onigbajumo@qut.edu.au
}

How to cite this paper: Adetunji, O., Ojo, S.S., Oyetunji, A. and Itua, N. (2021) Melting Time Prediction Model for Induction Furnace Melting Using Specific Thermal Consumption from Material Charge Approach. Journal of Minerals and Materials Characterization and Engineering, 9, 61-74. https://doi.org/10.4236/jmmce.2021.91005

Received: October 15, 2020

Accepted: January 18, 2021

Published: January 21, 2021

Copyright $\odot 2021$ by author(s) and Scientific Research Publishing Inc. This work is licensed under the Creative Commons Attribution International License (CC BY 4.0).

http://creativecommons.org/licenses/by/4.0/

\begin{abstract}
A system-level evaluation was used to analyze the induction furnace operation and process system in this study. This paper presents an investigation into the relationship between the instantaneous chemical composition of a molten bath and its energy consumption in steelmaking. This was evaluated using numerical modelling to solve for the estimated melting time prediction for the induction furnace operation. This work provides an insight into the lowering of energy consumption and estimated production time in steelmaking using material charge balancing approach. Enthalpy computation was implemented to develop an energy consumption model for the molten metal using a specific charge composition approach. Computational simulation program engine (CastMELT) was also developed in Java programming language with a MySQL database server for seamless specific charge composition analysis and testing. The model performance was established using real-time production data from a cast iron-based foundry with a 1 and 2-ton induction furnace capacity and a medium carbon-based foundry with a 10- and 15-ton induction furnace capacity. Using parameter fitting techniques on the measured operational data of the induction furnaces at different periods of melting, the results from the model predictions and real-time melting showed good correlation between $81 \%$ - 95\%. A further analysis that compared the relationship between the mass composition of a current molten bath and melting, time showed that energy consumption can be reduced with effective material balancing and controlled charge. Melting time was obtained as a function of the elemental charge composition of the molten bath in relation to the overall scrap material charge. This validates the approach taken by this research using material charge and thermodynamic of melting to optimize and better control melting operation in foundry and reduce traditional waste during iron and steel making.
\end{abstract}




\section{Keywords}

Charge Calculation, Mass and Energy Balance, Melting Time, Optimization, Induction Furnace, Numerical Model, Iron and Steelmaking, CastMELT

\section{Introduction}

The melting unit of the metallurgical foundry requires an enormous amount of energy and takes a major share of the production cost. Recent technological advancement in the use of iron and steel products has made the demand for high-quality cast products to be on the increase. This, however, did not come without an increase in the overall cost of production ranging from analytical chemical modifications of melt to the furnace parameter adjustments. To maximize the running cost of production and increase marginal profit, it becomes expedient for foundry managers to ensure production efficiency in every unit operation and the process involved in steel making. A wide variety of iron and steel with the strict quality required in the market all over the globe increasingly contribute largely to the development of new technologies and approach to optimization, utility, and efficiency need of steelmaking [1].

Simulation modelling development has consistently become a veritable tool for analyzing and predicting possible outcomes and performances obtainable in the foundry [2]. The induction furnace steel which contributes about $70 \%$ of secondary steelmaking operates by charging of cold scrap into it and melting takes place by the energy resulting from electromagnetic induction of the furnace system [3]. This occurs when the internal energy of the solid increases, typically by the application of heat or pressure, which increases the substance's temperature to the melting point. At the melting point, the ordering of ions or molecules in the solid breaks down to a less ordered state, and the solid melts to become a liquid. From a thermodynamics point of view, at the melting point, the change in Gibbs free energy $(\Delta G)$ of the material is zero, but there are non-zero changes in the enthalpy $(H)$ and the entropy $(S)$, known respectively as the enthalpy of fusion (or latent heat of fusion) [4] [5] and the entropy of fusion [6] [7]. Melting is therefore classified as a first-order phase transition. Melting occurs when the Gibbs free energy of the liquid becomes lower than the solid for that material. The temperature at which this occurs is dependent on the ambient pressure in the furnace [8].

According to Giacone and Manco, 2009 [9], improvement in systems energy efficiency measurement requires targeting of energy-saving opportunities in industrial processes. This is however noted to be challenging in that specialized knowledge of the processing system is highly required. One of the ways to achieve the needed optimization and reduce the production overhead in the melting unit of the foundry is through the analysis of the possible energy consumption requirement of every heat [10]. 
The downtime melting could, therefore, be reduced when the approximate time required for melting a scrap charge in the furnace is known. The actual melting time for successive heat can be utilized to control the loss time which is accrued to the overall production time and ensure proper monitoring of the melting shop workers to reduce operation downtime [11] [12] [13]. Since increased melting time implies a corresponding increase in the cost of electrical consumption charges as well as the life of refractory lining of the furnace, it is therefore of economic and technical advantage to control the melting time requirement with a view to ensuring optimization in the connecting parameters [12] [13] [14] [15] [16]. This would, however, require an understanding of the system process and obtaining a mathematical model that connects the system parameters for modification.

Using system-level evaluation, this study provides a theoretical measurement of the induction furnace melting time using the energy consumption approach via thermodynamic analysis of the material species in the furnace for successive heats.

\section{Materials and Method}

The first phase of steelmaking using induction furnace melting is the scrap charging which could be done manually or by mechanical systems depending on the size and type of the induction furnace [2]. To achieve the desired final melt composition, initial charge preparation must have been done prior to scrap charging. The energy consumption of the melting campaign can be increased at a significant level when the charging practice is done incorrectly [2] [3].

Minimizing energy consumption requires that bulk density materials above 1 $\mathrm{t} / \mathrm{m}^{3}$ are first charged up to $50 \%$ of the furnace active capacity before light scrap materials [2] [17]. The major raw materials for induction furnace melting for secondary steelmaking are steel scraps, iron scraps, sponge iron, pig iron, ferroalloys, mill scale, and carburizers [2] [17] [18]. Using contaminated or dirty scraps will not only impact the overall energy consumption and melting time of the induction furnace but also reduce the effective diameter of the furnace making charging a much difficult operation. This also brings about an increase in the amount of slag with about $10 \mathrm{kWh}$ energy loss per $1 \%$ slag that is formed [18] [19].

To accurately determine the melting time of an induction furnace campaign, real-time analysis of the melt constituent is a key step. A numerical model to predict induction furnace melting time using the melt chemistry energy consumption is discussed in this section.

\subsection{Melting Time Prediction Modelling}

\subsubsection{Actual State Enthalpy Analysis}

The theory of steel melting in the induction furnace is a state-dependent operation which is derived from the second law of thermodynamics, which is given by 
relationship between the amount of energy supplied, the internal energy of the material system and the work done within the system [14] [16]. From the equation

$$
\mathrm{d} E=\mathrm{d} U=\mathrm{d} q+\mathrm{d} w
$$

from $\mathrm{d} w=p \mathrm{~d} V$ or $V \mathrm{~d} p$

$$
\mathrm{d} H=\mathrm{d} U+p \mathrm{~d} V+V \mathrm{~d} p
$$

if all the work is taken to be in the form of expansion, therefore,

$$
\mathrm{d} H=\mathrm{d} q
$$

by differentiation of Enthalpy as a function of Temperature and Pressure, we have

$$
\mathrm{d} H=\left(\frac{\delta H}{\delta T}\right) p \mathrm{~d} T+\left(\frac{\delta H}{\delta T}\right) T \mathrm{~d} p
$$

Most pyrometallurgical operations are considered to occur at constant pressure, hence, $\partial H / \partial p$ is very negligible [13].

$$
\mathrm{d} H=\left(\frac{\delta H}{\delta T}\right) p \mathrm{~d} T=C_{p} \text { (Heat capacity) at constant temperature }
$$

By integration,

$$
H_{2}-H_{1}=\int_{T_{1}}^{T_{2}} C_{p} \mathrm{~d} T
$$

Heat capacity is a function of temperature represented in a polynomial form by

$$
C_{p}=a+b T+c T^{2}
$$

\subsubsection{Analysis Using Mass Composition Balance}

In a bid to ensure a measurable optimization and production planning efficiency an energy consumption model which is derived from the material charge input is proposed. This will allow the user to obtain the energy implication of the off-shop schedule planning activity using a charge optimization planning method which includes the amount of energy required to melt an aggregate scrap burden, the energy implication of the choice of scrap usage and the overall melting time. This route is quite beneficial as it will assist in projecting the cost implication of the overall production schedule of which melting time analysis is a major cost index. The model, therefore, takes into account the thermodynamic properties of the individual elemental composition of the overall charge meltdown.

From Equation (7), the amount of heat energy absorbed by each elemental specie in the molten burden is expanded as

$$
\text { (Fe, Si, Mn, C, P, S, Cr, Ni, Al) } \sum W_{m}\left(\int_{25}^{T_{t}} a+b T+c T^{-2}\right)+\left(W_{m} L_{f}\right)
$$

where $W_{m}$ is the mass density of melt in the furnace.

$T_{t}=$ instantaneous temperature of the melt at a given time and $L_{f}$ is the Latent Heat of fusion. 


\subsubsection{Thermal Energy Consumption Analysis}

In line with the study of Arasu and Rogers [14], the energy accounting method should define the areas of high energy use, energy waste and should point out areas in which energy saving can be accomplished. Arriving at the energy consumption pattern is the most important part of the energy audit. Energy consumption analysis for this research is designed to consider the material species of melting schedule per time bearing in mind that energy consumption changes from one melt operation to another.

Taking a theoretical approach would mean that the values of energy consumption obtained would be an incorrect evaluation. According to Chiluvera et al. [15], the actual power consumption values in foundry melting operation, when compared with the theoretical consumption, are almost double the theoretical energy value. This poses the need to develop an analytical model that will estimate the actual amount of energy consumed in peculiar foundry melting devices using the principle of thermodynamics and heat transfer principles as they apply in the heat balance equation [16].

Using the principle of heat energy balance,

Heat input $=$ Heat absorbed by the material system

$$
+ \text { Heat loss + redundant heat }
$$

Electrical energy input channel of the induction furnace is analysed according to Equation (10).

$$
E_{\text {in }}=Q_{c h}+Q_{e}+Q_{w}+Q_{f w}+Q_{r}
$$

$E_{\text {in }}$ is the electrical energy input to the furnace (usually as a function of the furnace power rating)

$$
E_{\text {in }}=I^{2} R T
$$

$Q_{c h}$ is the heat consumption/absorbed by the charged burden. As expressed in Equation (12),

$$
\begin{aligned}
Q_{c h}= & (\mathrm{Fe}, \mathrm{Si}, \mathrm{Mn}, \mathrm{C}, \mathrm{P}, \mathrm{S}, \mathrm{Cr}, \mathrm{Ni}, \mathrm{Al}) \sum M_{e}\left(\int_{25}^{T_{t}} a+b T+c T^{-2}\right) \\
& +\left(M_{e^{b t}} L_{f}\right)(\mathrm{kJ})
\end{aligned}
$$

where $M_{e}$ is the mass of elemental species in the melt composition.

$T_{t}$ is tapping temperature;

$\int_{25}^{T_{t}} a+b T+c T^{-2}$ is thermal capacity of the constituent element in the melt;

$M_{e^{b t}}$ is the mass of elemental species with melting temperature below the tapping temperature;

$L_{f}$ is the latent heat of fusion;

$Q_{e}$ is the heat loss to hysteresis (electromagnetic induction coil).

With reference to the study of Anuwat et al. [16]

$$
Q_{e}=4 I^{2} i n v * R^{2} c u
$$

$R^{2} \mathrm{cu}=$ resistance of the coil in the converter measured in ohms.

$4 I^{2}$ inv is the current of the inverter measured in amperes. 
Theoretically,

$$
\begin{gathered}
4 I^{2} \text { inv }=(0.16-0.2 \%) \text { of } E_{\text {in }} \\
Q_{w}=M_{w} C_{p} \mathrm{~d} v * \Delta T
\end{gathered}
$$

where $M_{w}$ is the mass flow rate of the cooling water around the induction furnace $(\mathrm{kg} / \mathrm{sec})$;

$C_{p} \mathrm{~d} v$ is the volumetric thermal capacity of water $\left(\mathrm{kJ} / \mathrm{m}^{3} \mathrm{~K}\right)$;

$\Delta t$ is the melting time (secs);

$Q_{f w}$ is the heat loss to furnace wall.

$$
Q_{f w}=0.001\left(T_{m}-T_{w}\right) / R
$$

where $T_{m}$ is the tapping temperature of the liquid metal;

$T_{w}$ is the temperature of the flowing water jacket;

$R$ is the heat resistance of the furnace lining $(\mathrm{kW} / \mathrm{K})$.

Theoretically,

$$
Q_{f w}=0.16 E_{\text {in }}
$$

$Q_{r}$ implies other heat losses (bar condenser, transformer, slag, fluxes, radiation).

\subsection{Melting Time Analysis}

The theoretical values are parameters according to the working operating conditions of the induction furnace.

Solving Equations (13)-(17), we have

Power consumption per Ton of melt

$$
\left(Q_{c h}\right)=\left(\varepsilon * Q_{c h}\right) * 0.28 \text {, expressed in }(\mathrm{kW})
$$

where $\varepsilon$ is the factor of induction heat loss $=2.898$.

Equating with Equation (14), we have

$$
E_{\text {in }} \Delta t=\left(\varepsilon * Q_{c h}\right) * 0.28 * W_{m}
$$

where $W_{m}$ is the weight in $\mathrm{kg}$ of the melt in the furnace.

From Equation (19),

$$
\text { Melting Time }(\Delta t)=\left(\left(\varepsilon * Q_{c h}\right) * 0.28 * W_{m}\right) / E_{\text {in }}
$$

$E_{i n}$ is the induction furnace power rating (specification).

Approximate furnace power rating for the induction furnace can be estimated using Equation (21)

$$
E_{\text {in }}=\operatorname{Std} . E_{\text {in }} * C_{f}
$$

where Std. $E_{\text {in }}$ is standard power consumption (depending on the type of metal burden) and $C_{f}$ is furnace capacity.

\subsection{Experimental Investigation}

To establish the aim of the study, the theoretical model developed by utilizing the thermal energy consumption from specific charge composition approach 
was subjected to test using real-time operational data at two different industrial sites.

Six (6) melting campaign were obtained at the foundry-A for cast iron production and six (6) melt campaign at foundry-B for medium carbon low alloy steel production at different times. A total of four (4) days was spent to obtain operational data for cast iron at foundry-A site and three (3) days for operation data for low-alloy medium carbon steel production at the site of foundry-B. Foundry-A induction furnace capacities are 1 and 2 tons while foundry-B induction furnace capacities are 10 and 15 tons. Real-time simulation using the same operational data of both foundry shops were performed using the developed model through a computational simulation program engine (CastMELT), written in Java and MySQL database server to run the numerical models. The relationship between predicted data and real-time melting shop experiments were analysed using statistical tools in MS Excel.

\section{Results and Discussion}

\subsection{Validation of Thermal Energy Consumption}

Table 1 and Table 2 show foundry operation data for cast iron production (foundry-A) and medium carbon steel (foundry-B). The data for foundry-A (Table 1) provides information such as scrap type (steel, cast iron, and foundry returns), ferro additive type (medium carbon FeMn, high carbon FeMn, FeCr, and $\mathrm{FeSi}$ ), the weight of scrap and ferroalloy charge, tapping temperature, cycle time (tap-to-tap time which includes all-time losses), the furnace capacity and the furnace power rating which determines the melting rate. For foundry-A, each melting campaign had their respective target compositions (see complete production data in supplementary materials 1 and 2).

Efforts were made on-site to ensure scrap selection was done closest to target final composition using an Excel-based, custom-made spreadsheet on site. This is possible since the furnace capacity was relatively small, and the weight of scrap needed could be easily managed for the spectro-analyzer in every melt campaign. Foundry-B (Table 2) provides similar information as obtained on the operational data for foundry-A. Chemical composition at any instance of spectrometric analyses was also provided in the production record sheet for both foundries. However, aggregate scrap was utilized since the furnace capacity larger. The scraps were categorized into light and heavy scraps and were charged at $50 \%$ furnace capacity before the first sample (F1) is collected from the aggregate melt for analysis. An additional 30\% scrap charge was made, and the next sample was taken for analysis before alloying (BA) at an overall furnace utilization of $80 \%$. The final sample was taken before tapping and recorded as after alloy samples (AA). Other melt samples (based on material charge using the rule of thumb) were taken between BA and AA samples, depending on how further away the BA samples are from the final composition.

Table 3 shows the results of thermal energy consumption modelling using 
Table 1. Operational data for cast iron production in foundry-A.

\begin{tabular}{|c|c|c|c|c|c|c|c|c|c|}
\hline \multirow[t]{2}{*}{ Melt Sample \& Date } & \multirow[t]{2}{*}{ Heat No } & \multirow{2}{*}{$\begin{array}{l}\text { Cast } \\
\text { Prod. }\end{array}$} & \multicolumn{2}{|c|}{ Scrap Mix (Kg) } & \multicolumn{4}{|c|}{ Alloy/Additive (Kg) } & \multirow{2}{*}{$\begin{array}{c}\text { Total } \\
\text { Charge }\end{array}$} \\
\hline & & & Steel/Cast Iron & Fdr. Returns & MCFeMn & HCFeMn & $\mathrm{HCFeCr}$ & $\mathrm{FeSi}$ & \\
\hline 04/05/2017 & 105171212 & NFMN128C & 850 & $\begin{array}{c}400(18 \mathrm{Mn}) \\
+ \\
200(14 \mathrm{Mn})\end{array}$ & $80 / 25$ & $50 / 3$ & 25 & $0 / 3$ & 1633 \\
\hline Chemical Ana. & C & SI & MN & NI & CR & $\mathbf{P}$ & & & \\
\hline Actual Melt & 1.11 & 0.64 & 11.98 & 0.06 & 2.64 & 0.03 & & & \\
\hline 1st Spark & 1.11 & 0.78 & 12.85 & 0.06 & 2.64 & 0.03 & & & \\
\hline \multirow[t]{2}{*}{ AIM } & $0.9-1.2$ & $0.6-0.8$ & $12.0-13.0$ & $0.5 \mathrm{Max}$ & $1.5-2.0$ & 0.07Max & & & \\
\hline & & & Steel/Cast Iron & Fdr. Returns & $\mathrm{FeSi}$ & MCFeMn & $\mathrm{HCFeCr}$ & & $(\mathrm{kg})$ \\
\hline $04 / 05 / 2017$ & 105171211 & NFMN-18 & 850 & 850 & 10 & $240 / 80$ & $30-\mathrm{Oct}$ & & 2070 \\
\hline Chemical Ana. & C & SI & $\mathrm{MN}$ & NI & CR & $\mathbf{P}$ & & & \\
\hline Actual Melt & 1.07 & 0.86 & 14.38 & 0.09 & 1.54 & 0.05 & & & \\
\hline 1st Spark & 1.12 & 0.84 & 16.81 & 0.04 & 1.75 & 0.04 & & & \\
\hline \multirow[t]{2}{*}{ AIM } & $1.0-1.2$ & $0.6-0.8$ & $16.0-18.0$ & $0.5 \mathrm{Max}$ & $1-2.5$ & 0.07Max & & & \\
\hline & & & Steel/Cast Iron & Fdr. Returns & $\mathrm{FeSi}$ & HCFeMn & $\mathrm{HCFeCr}$ & $\mathrm{LCFeCr}$ & $(\mathrm{kg})$ \\
\hline $04 / 05 / 2017$ & 10517611 & NF11055-O & 700 & & $5 / 8$ & 7-Oct & 15 & 75 & 820 \\
\hline Chemical Analysis & $\mathrm{C}$ & SI & MN & $\mathrm{NI}$ & CR & $\mathrm{P}$ & & & \\
\hline Actual Melt & 0.27 & 0.86 & 14.38 & 0.09 & 1.54 & 0.05 & & & \\
\hline 1st Spark & 1.12 & 0.84 & 16.81 & 0.04 & 1.75 & 0.04 & & & \\
\hline \multirow[t]{2}{*}{ AIM } & $0.2-0.3$ & $0.6-1.0$ & $0.8-1.5$ & 0.05 & $6.0-8.0$ & 0.03 & & & \\
\hline & & & Steel/Cast Iron & Fdr. Returns & $\mathrm{FeSi}$ & MCFeMn & $\mathrm{HCFeCr}$ & & $(\mathrm{kg})$ \\
\hline $5 / 05 / 2017$ & 8517611 & NFMN128C & 800 & & $0 / 2$ & 180 & $20 / 10 /$ & & 1012 \\
\hline Chemical Ana. & $\mathrm{C}$ & SI & $\mathrm{MN}$ & NI & CR & $\mathrm{P}$ & & & \\
\hline Actual Melt & 0.98 & 0.21 & 13.03 & 0.03 & 1.66 & 0.03 & & & \\
\hline 1st Spark & 1.05 & 0.59 & 12.89 & 0.03 & 1.9 & 0.03 & & & \\
\hline \multirow[t]{2}{*}{ AIM } & $0.9-1.2$ & $0.6-0.8$ & $12.0-13.0$ & 0.5 & $1.5-2.0$ & 0.07 & & & \\
\hline & & & Steel/Cast Iron & Fdr. Returns & $\mathrm{FeSi}$ & MCFeMn & & & $(\mathrm{kg})$ \\
\hline $8 / 05 / 2017$ & 85171221 & BS3100AW2 & $2000 / 875 /$ & & $0 / 0 / 15$ & $0 /-/ 50$ & & & 2940 \\
\hline Chemical Analysis & $\mathrm{C}$ & SI & $\mathrm{MN}$ & NI & CR & $P$ & & & \\
\hline Actual Melt & 0.88 & 0.25 & 0.6 & 0.04 & 0.05 & 0.02 & & & \\
\hline 1st Spark & 0.51 & 0.1 & 0.35 & 0.03 & 0.08 & 0.02 & & & \\
\hline 2nd Spark & 0.49 & 0.47 & 1.6 & 0.03 & 0.08 & 0.02 & & & \\
\hline \multirow[t]{2}{*}{ AIM } & $0.4-0.5$ & $0.55-0.7$ & $0.8-1.2$ & 0.05 & 0.3 & 0.07 & & & \\
\hline & & & Steel/Cast Iron & Fdr. Returns & $\mathrm{FeSi}$ & HCFeMn & & & $(\mathrm{kg})$ \\
\hline $9 / 05 / 2017$ & 95171221 & BS3100AW2 & 1900 & $0 / 150$ & $0 / 14$ & $0 / 30$ & & & 2094 \\
\hline Chemical Ana. & $\mathrm{C}$ & SI & $\mathrm{MN}$ & NI & CR & $\mathrm{P}$ & & & \\
\hline Actual Melt & 0.06 & 0.001 & 0.1 & 0.01 & 0.03 & 0.02 & & & \\
\hline 1st Spark & 0.39 & 0.59 & 1.14 & 0.02 & 0.04 & 0.02 & & & \\
\hline AIM & $0.4-0.5$ & $0.55-0.7$ & $0.8-1.2$ & 0.05 & 0.3 & 0.07 & & & \\
\hline
\end{tabular}




\begin{tabular}{|c|c|c|c|c|c|c|c|c|c|}
\hline & & & Steel/Cast Iron & Fdr. Returns & $\mathrm{FeSi}$ & HCFeMn & Graphite & $\mathrm{LCFeCr}$ & $(\mathrm{kg})$ \\
\hline $9 / 05 / 2017$ & 9517611 & NF11055-O & 900 & & $05 / 6.5$ & $0 / 5$ & $0 / 4.5$ & 105 & 1026 \\
\hline Chemical Ana. & $\mathrm{C}$ & SI & MN & NI & $\mathrm{CR}$ & $\mathrm{P}$ & & & \\
\hline Actual Melt & 0.08 & 0.23 & 0.53 & 0.06 & 5.25 & 0.02 & & & \\
\hline 1st Spark & 0.43 & 0.63 & 0.95 & 0.06 & 5.09 & 0.02 & & & \\
\hline AIM & $0.2-0.3$ & $0.6-1.0$ & $0.8-1.5$ & 0.05 & $6.0-8.0$ & 0.03 & & & \\
\hline
\end{tabular}

Table 2. Operational data for cast iron production in foundry-B.

\begin{tabular}{|c|c|c|c|c|c|c|c|c|c|c|c|c|c|}
\hline $\begin{array}{l}\text { Prod } \\
\text { No. }\end{array}$ & $\begin{array}{c}\text { Batch } \\
\text { No. }\end{array}$ & $\begin{array}{l}\text { Total } \\
\text { Melting } \\
\text { Time }\end{array}$ & $\begin{array}{l}\text { Starting } \\
\text { Time }\end{array}$ & $\begin{array}{l}\text { End } \\
\text { Time }\end{array}$ & $\begin{array}{c}\text { Light } \\
\text { Scrap } \\
(\mathrm{kg})\end{array}$ & $\begin{array}{c}\text { Heavy } \\
\text { Scrap } \\
(\mathrm{kg})\end{array}$ & $\begin{array}{c}\text { Bundle/Rebar } \\
(\mathrm{kg})\end{array}$ & $\begin{array}{c}\text { Total } \\
\text { Scrap } \\
(\mathrm{kg})\end{array}$ & $\begin{array}{c}\text { Power } \\
\text { consumption } \\
(\mathrm{kWh})\end{array}$ & $\begin{array}{l}\text { Tap to } \\
\text { Tap } \\
\text { Time } \\
\text { (mins) }\end{array}$ & $\begin{array}{l}\text { Tapping } \\
\text { Temp } \\
\left({ }^{\circ} \mathrm{C}\right)\end{array}$ & $\begin{array}{l}\text { Wt. of } \\
\text { Alloy } \\
\text { (SiMn) }\end{array}$ & $\begin{array}{c}\text { Total Wt. } \\
\text { of Billet } \\
(\mathrm{kg})\end{array}$ \\
\hline 1 & 1170345 & 102 & $7: 18 \mathrm{PM}$ & $10: 50 \mathrm{PM}$ & 6200 & 2270 & nil & 8470 & 9768.1 & 102 & 1886 & 122 & 8210 \\
\hline 2 & 1170346 & 110 & 11:05 PM & 2:02 AM & 8115 & nil & 1745 & 9860 & 10620.5 & 110 & 1793 & 149 & 5660 \\
\hline 3 & 2170341 & 97 & 10:50 PM & 1:00 AM & 4150 & nil & 4150 & 8300 & 8252.9 & 90 & 1804 & 140 & 8100 \\
\hline 4 & 2170342 & 115 & $1: 10 \mathrm{PM}$ & 4:07 PM & 5825 & 2080 & 2775 & 11400 & 14057.7 & 115 & 1800 & 85 & 11260 \\
\hline 5 & 2170343 & 99 & 7:34 PM & 9:40 PM & 4815 & 2755 & 2030 & 9600 & 8741.4 & 99 & 1782 & 120 & 9400 \\
\hline 6 & 2170345 & 105 & $12: 12 \mathrm{PM}$ & $2: 25 \mathrm{PM}$ & 6850 & nil & 2850 & 9700 & 8950 & 105 & 1799 & 130 & 9455 \\
\hline
\end{tabular}

NL: New Lining/F1: First furnace sample/BA: Before Alloy/AA: After Alloy.

Table 3. Thermal energy consumption for successive heat with respective bath analysis using the developed CastMELT simulation engine.

\begin{tabular}{|c|c|c|c|c|c|c|c|c|c|c|}
\hline \multirow{2}{*}{$\begin{array}{l}\text { Heat } \\
\text { No }\end{array}$} & \multirow{2}{*}{$\begin{array}{c}\text { Total } \\
\text { Charged } \\
\text { Weight }(\mathrm{kg})\end{array}$} & \multirow{2}{*}{$\begin{array}{c}\text { Tapping } \\
\text { Temperature } \\
\left({ }^{\circ} \mathrm{C}\right)\end{array}$} & \multirow{2}{*}{$\begin{array}{l}\text { Thermal Energy } \\
\text { Consumption (kW) }\end{array}$} & \multicolumn{7}{|c|}{ Elemental Specie Mass Composition (kg) } \\
\hline & & & & $\mathrm{C}$ & $\mathrm{Si}$ & $\mathrm{Mn}$ & $\mathrm{Cr}$ & $\mathrm{Ni}$ & $\mathrm{Cu}$ & $\mathrm{Fe}$ \\
\hline \multicolumn{11}{|c|}{ Cast iron production } \\
\hline 105171212 & 1633 & 1508 & 970.31 & 18.315 & 12.648 & 211.03 & 42.37 & 0.964 & 2.247 & 1336.16 \\
\hline 105171211 & 2070 & 1508 & 1205.5117 & 23.486 & 17.47 & 352.74 & 30.49 & 1.7823 & 2.971 & 1629.539 \\
\hline 10517611 & 820 & 1580 & 506.61 & 2.865 & 12.94 & 123.33 & 12.35 & 0.722 & 1.203 & 664.858 \\
\hline 8517611 & 1012 & 1520 & 844.988 & 10.499 & 3.642 & 138.299 & 16.599 & 0.2996 & 1.800 & 844.998 \\
\hline 85171221 & 2940 & 1575 & 1760.4439 & 26.301 & 18.687 & 54.749 & 1.438 & 1.149 & 2.875 & 2813.186 \\
\hline 95171221 & 2094 & 1580 & 1241.0137 & 3.3295 & 10.646 & 26.049 & 0.6156 & 0.2052 & 3.074 & 2024.375 \\
\hline \multicolumn{11}{|c|}{ Medium carbon steel production } \\
\hline 1170345 & 8470 & 1886 & 9768.1 & 15.077 & 27.442 & 50.82 & 12.5356 & 6.6998 & 14.8225 & 8326.01 \\
\hline 1173046 & 9860 & 1793 & 10620.5 & 17.1564 & 34.7072 & 78.9786 & 1.1832 & 6.1526 & 15.776 & 9672.66 \\
\hline 2170341 & 8300 & 1804 & 8252.9 & 15.272 & 20.75 & 42.745 & 15.438 & 6.806 & 12.367 & 8208.7 \\
\hline 2170342 & 11,400 & 1800 & $14,057.7$ & 23.484 & 37.62 & 105.108 & 16.416 & 6.9768 & 16.188 & 11286 \\
\hline 2170343 & 9600 & 1782 & 8741.4 & 21.12 & 30.816 & 93.216 & 11.616 & 6.1632 & 13.728 & 9484.8 \\
\hline 2170345 & 9700 & 1799 & 8950 & 18.527 & 33.659 & 64.02 & 11.737 & 5.529 & 14.453 & 9593.3 \\
\hline
\end{tabular}


CastMELT simulations to predict the mass compositions of the final chemistry as obtained in the real-time foundry production with the variables recorded in the production record sheet (supplementary material 1 and 2). The chemical composition analysis was used to estimate the mass composition of elemental specie and calculate the thermal consumption requirements of the molten melt just before tapping was carried out at respective temperatures using the developed numerical model which was plotted in the simulation engine. The results of the analyses were used to obtain the corresponding melting time value of the foundry operation.

The production record in Table 1 and Table 2 shows the possibility of a relationship existing between the weight of charged materials, total energy consumption, and the melting time for various heats. This further strengthens the hypothesis of the model framework using the approach of energy consumption for elemental constituents of the melt to predict the heat energy requirement and obtain melting time for successive heats.

The melting time prediction of CastMELT simulation engine and real-time production data are presented in Figure 1 and Figure 2 for both foundries within $5 \%$ standard deviation error (see real time foundry data and CastMELT result in supplementary material 3 and 4). Using Pearson's correlation, squared

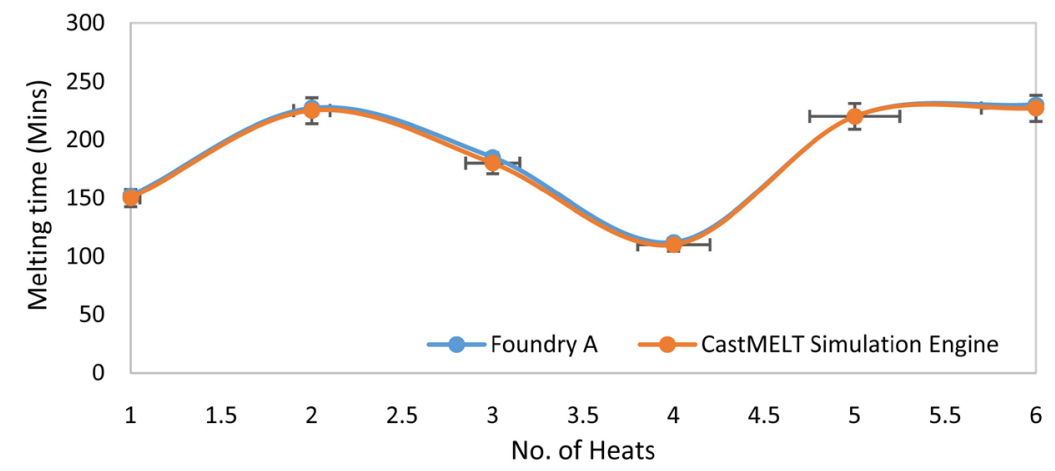

Figure 1. Melting time comparison between real time operation in foundry-A and CastMELT simulation engine.

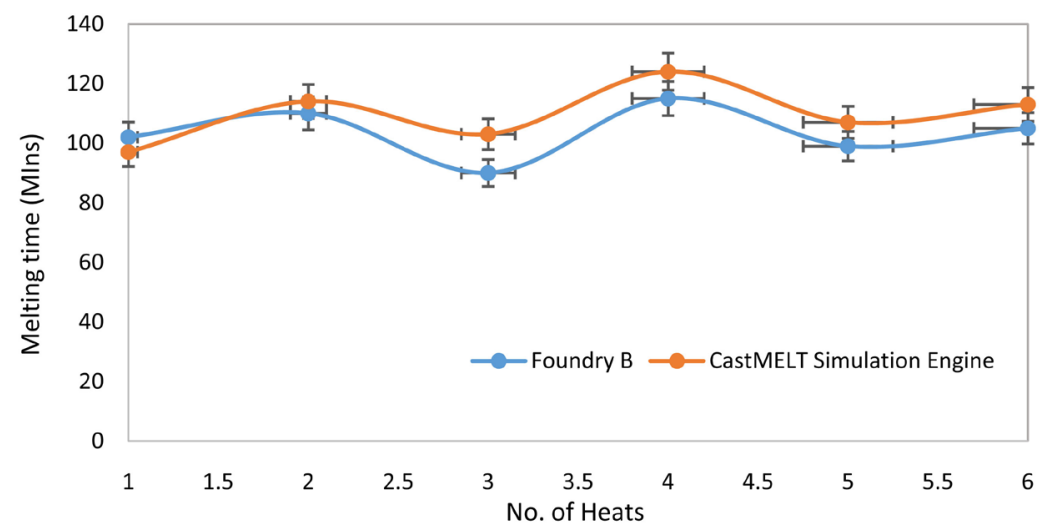

Figure 2. Melting time comparison between real time operation in foundry-B and CastMELT simulation engine. 
residential, standard error, and ANOVA statistical tools to ascertain predictability and model accuracy, cast iron production in foundry-A was predicted more accurately compared with the foundry-B steelmaking plant. Overall correlation and standard error of the outcome of the model (using simulation engine) and the real-time production data were $0.95 \%$ and $0.59 \%$ for foundry-A and $0.81 \%$ and $4.67 \%$ for foundry- $\mathrm{B}$, respectively. This result is mainly because of the correctness of the operational data presented in addition to foundry practice and plant scale.

While melting was done at a more controlled scale in foundry-A to meet the desired target melt, foundry-B had a greater degree of randomness and flexibility to accommodate real-life commercial structural steel production scenario especially with large scale complex utilizing aggregate scrap charge. Other parameters which controlled overall melting time from tap-to-tap includes the furnace operator and foundry engineer's technical know-how, accuracy in documentation especially for the time loses to furnace recharging and variability in melting rate due to different power rating. Though the furnace was not switched off at subsequent charging above $50 \%$, the power supply was reduced to zero to allow the influx of cold-scrap charge which warms before the power is increased again. It is noteworthy to note that operational data was documented at a close and precautionary range in foundry A compared to $B$.

\subsection{Relationship between Energy Consumption and Material Charge}

To establish the importance of melting time prediction, the relationship between the mass compositions of $\mathrm{Fe}$ as an elemental species with the high percentage mass contribution to the melt was measured against the weight of the overall scrap charge. This relationship is presented in Figure 3 and Figure 4.

Earlier in Table 1 and Table 2, a correlation between the weight of scrap charged and the overall melting time was observed. In a simple analysis, an increased material charge will result in more melting time at a steady melting rate.

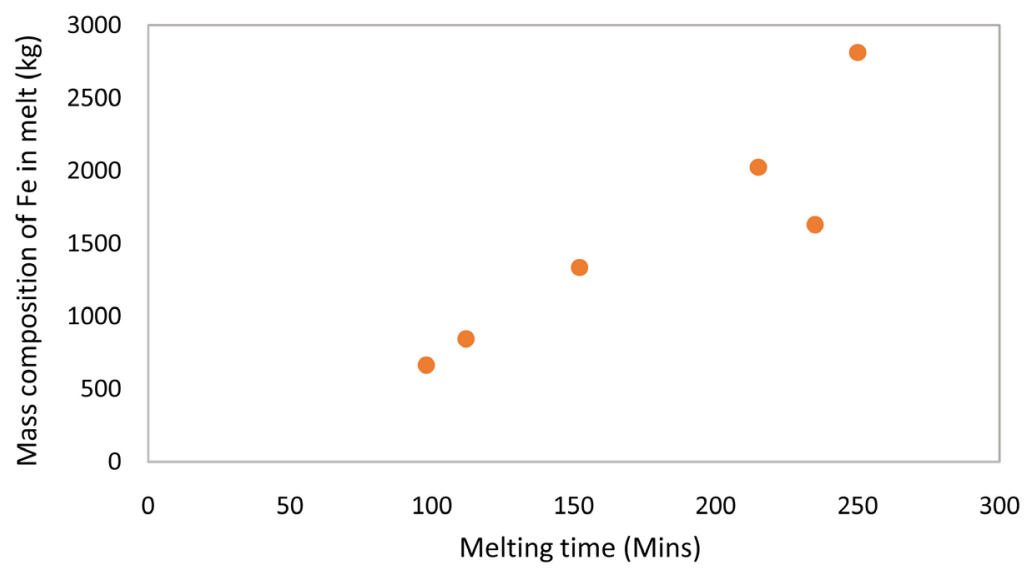

Figure 3. Effect of mass composition on the melting time for cast iron production in foundry A. 


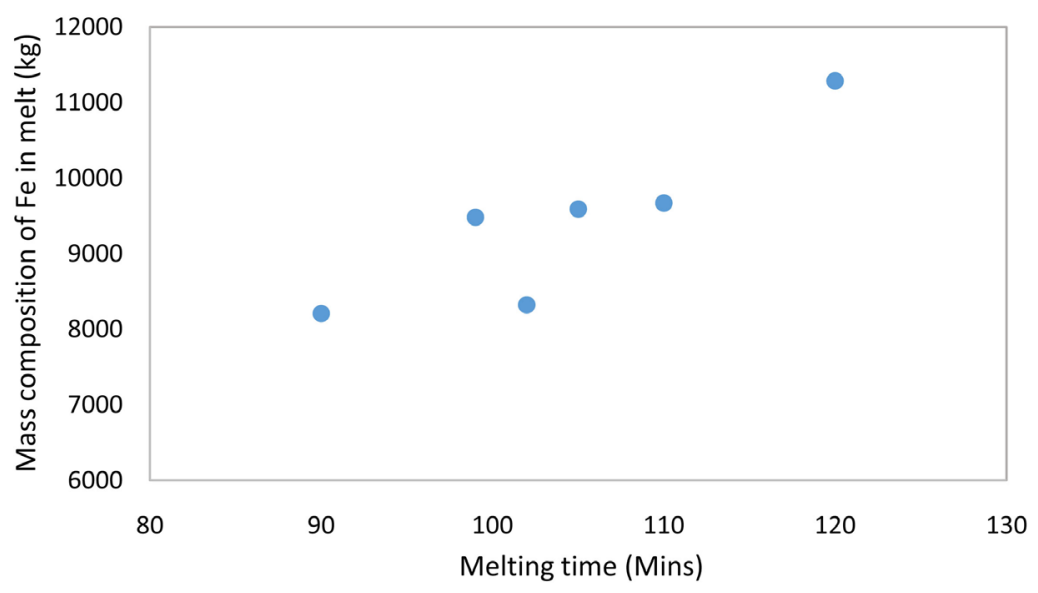

Figure 4. Effect of mass composition on the melting time for medium carbon steel production in foundry $\mathrm{B}$.

Therefore, if the material charge is controlled very closely, it will not only result in production cost savings in materials but consequently energy savings through reduced melting time. Figure 3 and Figure 4 show the relationship between the mass compositions of the (melt using Fe as representative of elemental specie) and melting time for foundry $\mathrm{A}$ and $\mathrm{B}$, respectively. It was observed that the melting time for an ongoing heat in the induction furnace is a function of the mass composition of the melt chemistry which is currently treated in the furnace bath. This remains valid for both cast iron in Figure 3 with R-squared value of 0.84 and medium carbon steel melts in Figure 4 with R-squared value of 0.79 that were investigated in the two foundry sites. The deviation in this result was due to operational shutdowns during melting due to power outage.

The implication of this relationship between melt composition (elemental and mass constituents) and melting time is that the more time spent in balancing the material composition of an existing charge to achieve target melt, the more energy is consumed in a real-time foundry operation. Having established this relationship from this study, foundry shops will be able to do more in reducing their melting time from material balancing and charge preparations which could be from virtual simulation engines such CastMELT [20] used in this study or others such as (NovaCast, OPTI Melt, Cloud Foundry, and MKW). These simulation programs are foundry melting support tool to assist foundry and production engineers to plan their melting campaign ahead for material charge and optimization. CastMELT simulation engine used in this research is a step ahead as it can be used to predict the expected melting time against the choice of scrap and ferroalloys and other additives.

\section{Conclusions}

In this study, theoretical modelling and experimental validation of induction melting time using real-time operational data are presented. The simulation program from previous study was used to engage mass balance composition 
analysis of successive melt chemistry, the elemental mass composition of constituent chemical specie, thermochemical requirement, furnace power rating/usage, electric and heat energy losses and attainable temperature as an approach to obtaining energy consumption requirement of scrap melting in the induction furnace. Thermochemistry parametrization was obtained using the final melt analysis and tapping temperature of the cast.

The validation study using a total of six melts each were obtained from cast iron and medium carbon steel foundries showed that thermal energy consumption for batch melting operation could be estimated and controlled using specific charge balancing approach. The comparison between real-time tap-to-tap time (less the charging time loses) and the model predictions for both foundries resulted in overall correlation and standard error of $0.95 \%$ and $0.59 \%$ (cast iron foundry) and $0.81 \%$ and $4.67 \%$ (medium carbon steel foundry) respectively. A further analysis which compared the relationship between the mass composition of a current molten bath and melting time showed that energy consumption can be reduced with effective material balancing and controlled charge.

Melting time was obtained as a function of the mass composition of the molten bath in relation to the overall material charge. Therefore, a controlled melting campaign would be an important approach to minimize production costs through reduced energy consumption. The use of the simulation engine used in this study from previous studies to run the developed melting time prediction model is considered to be useful program tool that will be able to support foundry men in achieving better control, flexibility, and prediction for induction furnace melting with reduced operation time and cost.

\section{Conflicts of Interest}

The authors declare no conflicts of interest regarding the publication of this paper.

\section{References}

[1] Czapla, M., Karbowniczek, M. and Michaliszyn, S. (2008) The Optimisation of Electric Energy Consumption in the Electric Arc Furnace. Archives of Metallurgy and Materials, 53, 559-565.

[2] Seidu, S.O. and Onigbajumo, A. (2015) Development of Charge Calculation Program for Target Steel in Induction Furnace. Leonardo Electronic Journal of Practices and Technologies, 6, 187-191.

[3] Seidu, S.O., Onigbajumo, A. and Olagunju, S. (2018) Development of Scrap Charge Maximization Program Capable for Melt Prediction and Modification in Crucible Furnace. European Journal of Applied Engineering and Scientific Research, 6, 1-9.

[4] Atkins, P. and Jones, L. (2008) Chemical Principles: The Quest for Insight. 4th Edition, W. H. Freeman and Company, United States of America, 236.

[5] Ghosh, A. and Chatterjee, A. (2008) Iron Making and Steelmaking: Theory and Practice. PHI Learning Pvt. Ltd, New Delhi, 80-83.

[6] Degarmo, E.P., Black, J.T. and Kohser, R.A. (2003) Materials and Processes in Manufacturing. 9th Edition, Wiley Publisher, New York, 277-280. 
[7] Jena, S. and Ravastngadi, S.T. (1992) Commissioning and Operating an Induction Furnace at Zimasco (KweKwe Division) to Melt Highcarbon Ferrochromium. In: Proceedings of the 6 th International Ferroalloys Congress, IFACON 6, Cape Town, Vol. 1, SAIMM, Johannesburg, 113-118.

[8] Ott, J.B. and Boerio-Goates, J. (2000) Chemical Thermodynamics: Advanced Applications. Academic Press, Cambridge, 92-93. https://doi.org/10.1016/B978-012530990-5/50011-0

[9] Giacone, E. and Mancò, S. (2012) Energy Efficiency Measurement in Industrial Processes. Energy, 38, 331-345. https://doi.org/10.1016/j.energy.2011.11.054

[10] Logar, V., Dovžan, D. and Škrjanc, I. (2012) Modelling and Validation of an Electric Arc Furnace: Part 2, Thermochemistry. ISIJ International, 52, 413-423.

https://doi.org/10.2355/isijinternational.52.413

[11] Nihar, B. (2013) Review Paper on Numerical Analysis of Induction Furnace. International Journal of Latest Trends in Engineering and Technology (IJLTET), 2, 178-184.

[12] Nyssen, P., Marique, C., Prum, C., Bintner, P. and Savini, L. (1998) New Metallurgical Model for the Control of EAF Operations. Centre De Recherches Métallurgiques, Liège, Vol. 15, 55-61.

[13] Upadhyaya, G.S. (1983) Metallurgical Thermodynamics and Kinetics. Pergamum Press, New York.

[14] Arasu, L. and Rogers, J.L. (2009) Energy Consumption Studies in Cast Iron Foundries. Transaction of 57 th India Foundry Congress, 57, 331-336.

[15] Chiluveru, P., Markandeya, R. and Datta, G.L. (2005) Actual Power Consumption of Alloy Steels-Experimental Results. International Journal of Scientific Research and Management (IJSRM), 3, 3363-3368.

[16] Anuwat, P., Krit, S. and Prapart, U. (2009) Temperature Estimation of Liquid Steel in Induction Furnace. Proceedings of the International Multi Conference of Engineers and Computer Scientists, Hong Kong, Vol. 2, 7-12.

[17] Yusuf, J.A. (2008) Investigations on the Effect of Cold Charge and Heel on the Productivity of Foundry Furnace and Effect on the Quality of Product. Journal of Minerals \& Materials Characterization \& Engineering, 7, 6-28.

[18] Jimbo, I. and Cramb, A.W. (1993). The Density of Liquid Iron-Carbon Alloys. Metallurgical Transactions B, 24, 5-10. https://doi.org/10.1007/BF02657866

[19] Abubakre, O.K. and Muriana, R.A. (2009) Mathematical Model for Optimizing Charge and Heel Levels in Steel Remelting Induction Furnace for Foundry Shop. Journal of Minerals \& Materials Characterization \& Engineering, 8, 417-425. https://doi.org/10.4236/jmmce.2009.86037

[20] Adetunji, O. and Seidu, S.O. (2020) Simulation and Techno-Economic Performance of a Novel Charge Calculation and Melt Optimization Planning Model for Steel Making. Journal of Minerals and Materials Characterization and Engineering, 8, 277-300. https://doi.org/10.4236/jmmce.2020.84017 